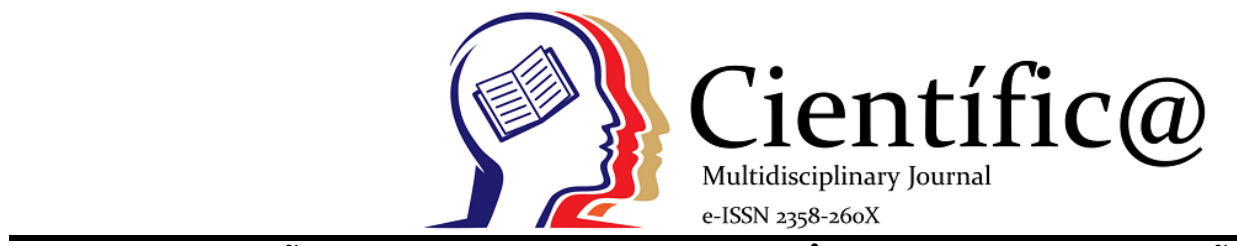

\title{
REFLEXÕES ACERCA DO DIREITO SISTÊMICO: DA CONSTELAÇÃO FAMILIAR E SUA APLICABILIDADE NO PODER JUDICIÁRIO
}

\author{
REFLECTIONS ABOUT SYSTEMIC LAW: FAMILY CONSTELLATION AND ITS APPLICABILITY \\ IN JUDICIAL POWER
}

\author{
Norton Maldonado Dias ${ }^{1}$, João Guilherme Scheffler ${ }^{2}$
}

${ }^{1}$ Professor da Faculdade de Direito de Sinop.
${ }^{2}$ Advogado. Graduado em Direito com pós-graduação pela Faculdade de Direito de Sinop - MT. Especilização com Trabalho na àrea do
Direito Sistêmico e Constelação familia

\section{Info}

Recebido: 20/12/2019

Publicado: $10 / 02 / 2020$

DOI: 10.29247/2358-260X.2019v6i2.p85-101

ISSN: 2358-260X

Palavras-Chave
Constelação Familiar. Direito Familiar.
Direito Sistêmico.

Keywords:

Family constellation, family law, systemic law.

\begin{abstract}
Resumo
O objeto do presente trabalho corresponde ao estudo do Direito Sistêmico, diante das novas ferramentas que passam a ser utilizadas na resolução dos conflitos, tais como a Constelação Familiar. Assim, trata-se da problemática questão da atualização do Judiciário, frente às mudanças de conceitos sociais e quebra dos paradigmas, uma vez que o desenvolvimento humano busca novas fontes de resolver os conflitos criados em sociedade. Na tentativa de alcançar este objetivo principal, correspondente a demonstrar a efetividade do Direito Sistêmico dentro do Poder Judiciário, a proposta procurou desenvolver primeiramente os aspecto moral, filosófico e científico, apresentando assim as bases da reforma do Código de Processo Civil. Do aspecto moral e filosófico, releva-se a necessidade de adequação de métodos que podem ser considerado muitas vezes, aos olhos dos leigos, misticismo, hermetismo, dentre outros conceitos prolixos. Já o fator científico, está delineado no presente trabalho em patamares muito relevantes, dentre os quais,
\end{abstract} destaca-se os estudos científicos que desenvolveram e aprimoraram os mecanismos da Constelação Familiar para que hoje pudesse estar sendo utilizada e bem aceita pelos Tribunais. Vale ainda ressaltar expressivas discussões acerca da aceitação dos juízes e tribunais quanto a utilização da ferramenta, bem como, da aceitação das partes na utilização para resolução dos conflitos. 0 trabalho se utiliza da metodologia dedutiva bibliográfica, utilizando-se como principais fontes a doutrina e jurisprudências, bem como, livros aprofundados que explicam o que é a Constelação Familiar. 0 trabalho visa demonstrar os benefícios da implementação cada vez maior do Direito Sistêmico, bem como, demonstrar quais os resultados obtidos até o presente momento. A pesquisa foi desenvolvida sondando a hipótese de que o Direito Sistêmico é uma inovação que pode ser o desafogamento do Poder Judiciário, e, quiçá, um grande passo no desenvolvimento da humanidade, uma vez que possibilita não só a resolução do conflito, mas também, coloca um ponto final em uma grande carga emocional e psicossomática relacionada com os conflitos que desencadearam a demanda judicial. 


\section{INTRODUÇÃO}

A pesquisa desenvolve o tema da Constelação Familiar e do Direito Sistêmico, haja vista a atualidade da discussão no sentido de que a ferramenta da Constelação Familiar tem sido muito utilizada no Judiciário nas audiências de conciliação e mediação.

Buscando desenvolver a temática, vale ressaltar o objetivo principal correspondente que é demonstrar a efetividade da aplicação do Direito Sistêmico, pois, embora se viva em um Estado Laico, a Constelação Familiar está, ainda, sendo vista de forma modesta, porém está sendo objeto de vários estudos que poderão alterar uma noção bastante abrangente e rica dentro da interdisciplinariedade, enfatizando a área da psicologia.

$\mathrm{Na}$ tentativa de alcançar este principal ponto, vale o desenvolvimento e o esforço em transcrever os elementos que servem de base para o presente trabalho, o tripé de sustentação, a Moral, a Filosofia e a Ciência, uma vez que tais elementos, são os métodos de experimentação que trouxeram à humanidade o desenvolvimento de todo o conhecimento que temos atualmente.

Em um segundo momento o trabalho enfatiza a questão jurídica do assunto, haja vista que para receber a ferramenta da Constelação Familiar e consequente implantação do Direito Sistêmico, foi necessária a realização de uma série de estudos que pudessem demonstrar que o instituto poderia ser uma nova porta da percepção, um salto para a humanidade.

Vale ressaltar a específica atenção que o trabalho deu às referências científicas, tendo em vista que, mesmo havendo divergência nas teses (correntes newtonianas da física clássica e pós newtonianas da física quântica), a ciência, através dos métodos de experimentação, é a base mais sólida que a humanidade tem em mãos para poder explicar os fenômenos que permeia a vidas dos seres terrenos.
Os objetivos desta investigação irão buscar responder a problemática questão que indaga acerca do que é o Direito Sistêmico e a Constelação Familiar, e quais tem sido os benefícios na aplicação judiciária. Nesse sentido o caminho a ser percorrido será através do método investigação científica através, também, dedução bibliográfica.

Esta metodologia será percorrida priorizando fontes bibliográficas, dentre as quais, Doutrinas Jurídicas, Doutrinas Filosóficas, Doutrinas Sistêmicas e Doutrinas Científicas, em razão do alto grau de complexidade do assunto e da necessidade de se apresentar a maior base de conhecimento possível aos leitores.

Também utilizará fontes legais e jurisprudenciais, tais como, alguns julgados e leis que serão utilizados, haja vista que todo esse material faz parte do arcabouço em que se assenta o desenvolvimento do tema, bem como, embora não seja possível trazer todos os elementos possível para eliminar qualquer dúvida, facilitará a compreensão e possibilitara um caminho para qualquer um que venha a possuir interesse em se aprofundar no assunto.

Diante do material colhido e aqui apresentado, o trabalho será desenvolvido tendo como hipótese consistente a crença de que o Direito Sistêmico pode estar se apresentando como uma oportunidade de um salto para a humanidade, pois, como dito anteriormente, os elementos que serão apresentados no decorrer do trabalho buscarão sanar qualquer dúvida, podendo, ao final, a hipótese vir a ser confirmada ou não pelo leitor, que poderá estender seus estudos futuramente nas doutrinas aqui apresentadas.

Reitera-se, justificativa, pela importante contribuição, tendo em vista, principalmente, os dados e índices verificados dos inúmeros processos e significativo numerário de litígios que foram 
solucionados por influência da prática constelar, ensejando o merecimento pela presente investigação.

\section{DAS NOÇÕES GERAIS DO DIREITO SISTÊMICO}

Uma nova era nasce com o Direito Sistêmico, muito porquê, nem o Contrato Social de Rousseau seria capaz de explicar os fatores de Campos Morfogenéticos assim como Rupert Sheldrake. O Direito Sistêmico traz um posicionamento na era da luz, para dissipar toda treva que possa estar servindo de empecilho ao desenvolvimento. Vejamos as considerações de Lacerda:

A expressão "direito sistêmico" compreende uma forma inovadora de se olhar, sentir e elaborar os conflitos judiciais por meio de uma abordagem terapêutica responsabilizadora e reflexiva que permite contato com dinâmicas invisíveis que motivam os conflitos e vinculam os comportamentos atuais, sugerindo passos direcionados a harmonização das relações familiares, sociais e empresariais por meio do equilíbrio, da ordem e do pertencimento. (LACERDA, 2017, p.03)

É com base nesses horizontes de percepção, de sensação e até mesmo de vivência que vem sendo construída as novas concepções de mundo e de vida, bem como, as bases do direito sistêmico.

O que nos faz abrir as portas para o entendimento do que é o Direito Sistêmico, dentro dos novos paradigmas das ciências em geral, é o que segue:

O Direito Sistêmico é, antes de tudo, uma postura. É uma nova forma de viver e de se fazer justiça, buscando o equilíbrio entre o dar e o receber, de modo a trazer paz para os envolvidos em um conflito. O Direito Sistêmico, em termos técnico-científicos, é um método sistêmico fenomenológico de solução de conflitos, com viés terapêutico, que tem por escopo conciliar, profunda e definitivamente, as partes, em nível anímico, mediante o conhecimento e a compreensão das causas ocultas geradoras das desavenças, resultando daí paz e equilíbrio para os sistemas envolvidos (STORCH, 2015, p. 95).

Este caso em específico, a situação antiga se altera totalmente, passando assim a possibilitar que as partes esteja sensitivamente menos sujeitas às próprias vicissitudes, subam em grau de consciência, sendo assim capazes de expandir suas possibilidades de experiência e, portanto, de conhecimento objetivo. Tal conceito seria a realidade imperceptível referendada por Lacerda:

O direito sistêmico é a tradução de um direito sensível, humanizado, inclusivo, que se sustenta na autonomia da vontade, na dignidade da pessoa, valendo-se de ações e intervenções sistêmicas que conduzam à responsabilização individual e reflexiva por meio de uma experiência pessoal de enfrentamento da realidade (verdade) imperceptível, que movimenta as relações humanas e por consequência atinge as relações processuais e o todo $\mathrm{O}$ sistema judiciário (LACERDA, 2017, p. 5).

As ferramentas do Direito Sistêmico, são capazes de realizar um levantamento de caráter psicológico, sociológico, indo além, diante de conceitos metafísicos, o Direito Sistêmico trabalha diretamente nos reflexos mecânicos da constituição corporal dos indivíduos, ou melhor, a manifestação das forças vitais, ou seja, tudo aqui que está entrelaçado com as paixões as sensações, os pensamentos e toda a sorte de atividades sensíveis. Isso permite a resolução definitiva dos conflitos, continua Lacerda:

No contexto das relações conflituosas, nasce um direito direcionado para a efetivação de garantias por meio de soluções pacificadoras enaltecendo o valor 
de cada pessoa. Assim, da comunidade jurídica dos operadores do direito emergem os gestores da justiça empenhados em conduzir conflitos judiciais em direção à paz reconhecendo ser este o mais significativo desejo de toda pessoa humana (LACERDA, 2017, p. 6).

Com a maior compreensão do Universo e da consciência humana, uma vez que, filósofos, psicólogos, médicos e sociólogos voltaram-se para o assunto referente aos conflitos humanísticos para solucionar os problemas, de modo que as soluções tais como o Direito Sistêmico e a Constelação Familiar vieram sendo desvendadas e passaram a agir energicamente, e o mais rápido possível. Tendo dito isso sabemos que as ferramentas:

Permitem a compreensão das dinâmicas dos conflitos e da violência de forma mais ampla, além das aparências, facilitando ao julgador adotar, em cada caso, o posicionamento mais adequado à pacificação das relações envolvidas (STORCH, 2016, p.1)

Para a compreensão do Direito Sistêmico, é necessário um estudo aprofundado da metafísica que envolve o campo de atuação, pois todo o trabalho é fruto de muito estudo, e é por isso que tem sido tão recomendado e têm dado resultados positivos.

O desenvolvimento da ferramenta vem instituído em conceitos organizacionais, em que o precursor e maior disseminador Bert Hellinger, por meio da compreensão de causa e efeito, concluiu que tudo tem sua razão de ser inclusive as limitações do nosso corpo e consciência em relação à nossa capacidade e posição no sistema familiar. Descreve:

\author{
Neste critério, também \\ denominado de hierárquico, o \\ decurso do tempo vinculado a \\ idade de cada integrante assegura a \\ coesão do grupo familiar e \\ proporciona paz ao sistema \\ (HELLINGER, 2003, p. 72).
}

conhecimento possível de si mesmo está indissoluvelmente ligado ao corpo, pois é através dele que agimos e sentimentos o mundo.

De acordo com os paradigmas familiares que o indivíduo foi inserido desde o seu nascimento, condicionou-se uma forma de agir e pensar, de dar e receber, logo, o indivíduo irá se comportar diante de todos os demais relacionamentos projetando seu conceito base de necessidade cognitiva, nos demonstra Hellinger:

A preservação da estabilidade
relacional se alcança com a
constante equiparação entre o
crédito e o débito gerado pelo dar
e o tomar de forma harmoniosa e
equivalente. Neste comando a
dinâmica perceptível decorrente da
compensação desequilibrada
poderá conduzir ao término do
relacionamento de casal
(HELLINGER, 2003, p. 77 ).

São os fatores de causa e efeito, que vem de uma rede muito extensa de indivíduos que estão todos interligados emocionalmente em um emaranhamento, uma teia de informações, de antepassados. Logo, um indivíduo com a sua base psicológico/moral/psicossomática desequilibrada é um fio solto no quadro social, e, no campo das infinitas possibilidades, é um fator prejudicial em grande escala, pois, havendo um individuo desequilibrado, é provável que todo o sistema familiar se encontre assim, senão vejamos: Logo, os sentidos fornecem dados e informações no capo morfogenético, logo, o
Uma pessoa atormentada por
motivos de origem familiar pode
desenvolver uma psicose, tornar-se
violenta e agredir outras pessoas.
Quem tem a ver com isso? Todos.
Toda a sociedade. Adianta
simplesmente encarcerar esse
indivíduo problemático, ou
mesmo 88ata-lo (como defendem
alguns)? Não. Se ele tiver filhos
que, com as mesmas raízes
familiares, apresentem os mesmos
transtornos, o problema social
persistirá. A solução sistêmica,
nesse caso, deve ter em vista a
origem familiar do indivíduo. Não
haverá real solução de outra forma
(STORCH, 2010, p.1)

Até que se possa progredir no sentido de

Uma pessoa atormentada por
motivos de origem familiar pode
desenvolver uma psicose, tornar-se
violenta e agredir outras pessoas.
Quem tem a ver com isso? Todos.
Toda a sociedade. Adianta
simplesmente encarcerar esse
indivíduo problemático, ou
mesmo 88ata-lo (como defendem
alguns)? Não. Se ele tiver filhos
que, com as mesmas raízes
familiares, apresentem os mesmos
transtornos, o problema social
persistirá. A solução sistêmica,
nesse caso, deve ter em vista a
origem familiar do indivíduo. Não
haverá real solução de outra forma
(STORCH, 2010, p.1)
moralizar os indivíduos com base na razão pura e prática, no 
desenvolvimento das virtudes através do auto-conhecimento, ferramentas como a Constelação Familiar serão os únicos método capazes de promover a paz e a segurança social.

\subsection{O Direito Sistêmico e o Sistema de Constelação Familiar de Bert Hellinger}

Tentaremos abordar tais elementos, tão específicos da melhor forma possível para a compreensão dos leitores deste trabalho, demonstrando a necessidade de que a comunidade jurídica esteja cada vez mais à par desta ferramenta.

Os efeitos são comprovados em estatísticas, não é necessário advogado para defender o Direito Sistêmico, os números falam por si mesmos, vejamos:

Tal importância foi reconhecida pelo CNJ em 2016 ao observar que quando ao menos uma das partes envolvidas participa de uma constelação antes da audiência de mediação, há um crescente índice de acordos nos processos (STORCH, 2017, p.2)

A Constelação Familiar é um método organizado de condução do caso, busca confortar e conscientizar as partes sobre a situação que envolve as dificuldades inerentes ao caso, possibilitando assim um equilíbrio, equilíbrio este que traz retorno efetivo em todos os casos em que há abertura para a solução do conflito, aponta Hausner:

Constelação é o coletivo de estrelas de um sistema, por isso a palavra originou o termo constelação familiar, onde o sujeito é o centro do sistema social em que se insere e vivencia naquele momento específico da constelação (HAUSNER, 2007, p. 123).

Em quase todos os casos, um dos indivíduos se sente excluído, se sente não pertencente àquele sistema que tem relação com a contenda, e inconscientemente, oferece resistência ao prosseguimento benevolente de sua própria vida.

A resistência é muito grande, apenas o olhar e acolhimento sistêmico que pode oferecer o constelador condutor da audiência deverá restabelecer a ordem no caso em concreto, in verbis:

A primeira ordem, de pertencimento, diz respeito ao fato de que, não importa o que uma pessoa faça, ela continuará com o mesmo direito de pertencer à família, à sociedade, ao mundo, independente de estar livre ou recluso ou de estar presente fisicamente na família atual ou não (HELLINGER, 2007, p.97).

Como seres sencientes, temos uma sensibilidade ligada com todos os indivíduos com quem compartilhamos a nossa vida, e procuramos ser olhados por todos que nos acompanham durante essa trajetória, e é claro, com respeito e dignidade. Bert Hellinger nos retrata isso de maneira específica:

Diz respeito a quem chegou primeiro no ordenamento familiar, ou seja, sempre os mais velhos merecem ser olhados com muito respeito e cuidado, pois é por meio deles que a família está assim instalada e existe efetivamente (HELLINGER, 2007, p.99).

O conflito possui uma ligação com aquilo que o indivíduo passa a esperar do outro, e isso na maioria das vezes, de maneira inconsciente, pode estar se desenvolvendo de maneira recíproca em uma relação entre os indivíduos, e isso pode estar relacionado com todo o sistema familiar, vejamos:

A lei do equilíbrio sempre existe nas ações de dar e receber e segue o raciocínio de que dentro de uma relação interpessoal, ambas as partes devem dar e receber para que haja um equilíbrio e seja encontrada a paz entre as pessoas pertencentes a um núcleo familiar (HELLINGER, 2007, p. 103). 
O homem é fruto do meio, aprende tudo aquilo que seu meio pode lhe ensinar. A falta de amor e afeto familiar à uma criança, fará com que ela cresça com esse trauma, e as informações serão reproduzidas em seus relacionamentos futuros.

Diante disso, entendendo que os fatores psicológicos não estão somente ligados aos fatos do caso em concreto, é preciso que haja conhecimento destes conceitos para uma efetiva condução das partes na resolução do conflito:

Durante a audiência o juiz, conciliador ou mediador também pode trazer questionamentos aos envolvidos utilizando frases ou "palavras-chave" que dão significado àquela situação de conflito, propiciando tomada de consciência do emaranhamento envolvido na questão, permitindo que as partes reconheçam sentimentos expostos, visualizando a importância de cada um e os possíveis caminhos para que o conflito se desfaça ou se minimize (VALL, 2017, p. 18).

Não se pode colocar vinho novo em odres velhos, já dizia o ditado bíblico, é preciso que os conceitos de conhecimento nestes casos tenham muita informação de que os indivíduos são possuidores de traumas e da mais diversas formas de qualidade moral, raciocínio, vícios de toda natureza, preconceitos e toda sorte de atributos que constituem a individualidade do ser.

As obras do ilustríssimo Carl Jung podem nos dar a compreensão do que Vall nos traz em conceito:

\footnotetext{
A resolução do conflito se dá para além do olhar focado no ordenamento jurídico, mas alia o ordenamento do amor, é mediante as ordens do amor (de pertencimento, de hierarquia e equilíbrio) que a resolução de conflitos e problemas surge. $\mathrm{O}$ amor inevitavelmente está presente, seja consciente ou inconscientemente. Com o amor, a solução é alcançada (VALL, 2017, p.19).
}

Ora, como se poderia falar que o amor, algo tão abstrato poderia um dia ser utilizado para resolver conflitos? Sabemos que os sentimentos de toda ordem estão diretamente e cientificamente relacionados com os estímulos hormonais, a produção de Dopamina, Endorfina, Serotonina, etc.

Não precisamos entrar nessa dimensão para compreender que o cérebro possui uma programação, cheia de mecanismos capazes de receber estímulos e formular efeitos, o capítulo da ciência buscou explicar de maneira menos complexa. A constelação busca uma incisão direta nesta relação de causa e efeito, com a menor invasão possível, vejamos:

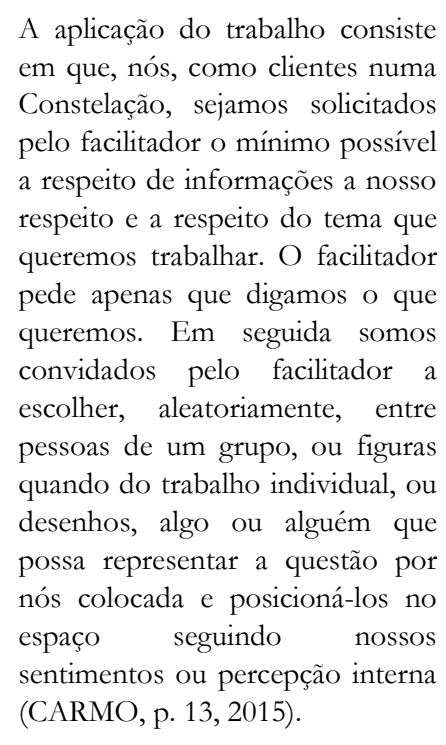

Se acreditarmos que a parte consciente do nosso cérebro represente apenas $5 \%$ do que realmente temos controle, $95 \%$ é subconsciente, e é exatamente essa parte do cérebro que leva todos nós a agir conforme os impulsos dos estímulos que recebemos durante toda a vida.

É preciso compreender que o problema nunca está na superfície, é necessário que se foque na parte do Ice Berg que se encontra submersa:

O direito sistêmico se propõe a encontrar a verdadeira solução. Essa solução não poderá ser nunca para apenas uma das partes. Ela 
sempre precisará abranger todo o sistema envolvido no conflito, porque na esfera judicial - e às vezes também fora dela - basta uma pessoa querer para que duas ou mais tenham que brigar. Se uma das partes não está bem, todos os que com ela se relacionam poderão sofrer as consequências disso (STORCH, 2010, p.5).

A busca real é cessar o sofrimento que está sendo causado pelo conflito, pois, em razão da falta de conhecimento (auto-conhecimento) da humanidade, os seres humanos não foram educados para lidar com o lixo emocional, e isso gera um dano em ricochete em todas as relações:

\begin{abstract}
As constelações familiares são regidas por ordens do amor, o reconhecimento dessas ordens permite compreender de forma clara quais são os conflitos que assolam um sistema familiar, direcionando o julgador a adotar o posicionamento mais adequado ao caso concreto, sendo assim, tem-se como Direito Sistêmico a junção do Direito aliado a técnica de Constelações Familiares (SILVA, 2016, p.5)
\end{abstract}

O Direito Sistêmico busca demonstrar o que estão por trás das cortinas da humanidade, por trás do conflito, desmascarar as vontades, e mais, busca solucionar definitivamente o problema. O magistrado STORCH explica isso de maneira clara e precisa:

Mesmo tendo as leis positivadas como referência, as pessoas nem sempre se guiam por elas em suas relações e os autos de um processo judicial dificilmente refletem essa realidade complexa. Assim, por meio deste método, vêm à tona dinâmicas que estavam ocultas naquela família, conflitos e traumas que envolveram antepassados e que projetaram seus afeitos ao longo das gerações seguintes, causando os efeitos atualmente sentidos pelo cliente (STORCH, 2010, p.7)

Que outro método poderia apresentar um índice de $100 \%$ em sua abordagem na solução de conflito? A mediação e conciliação não são novidade em nosso ordenamento jurídico, pode se perceber que o que está faltando era o nível de conhecimento adequado para aplicação, faltava adequar os meios aos fins. Vejamos a publicação do CNJ sobre a utilização da ferramenta da Constelação Familiar:

Com ajuda da chamada
Constelação Familiar, [...], o
magistrado Sami Storch conseguiu
índice de acordo de $100 \%$ em
processos judiciais onde as partes
participaram do método
terapêutico. Já no Tribunal de
Justiça de Mato Grosso do Sul, a
Constelação Familiar passou a ser
implantada por meio da
formalização de um convênio
entre a Coordenadoria da Infância
e Juventude (CIJ) com um grupo
de terapeutas sistêmicos
(CONSELHO NACIONAL DE
JUSTIÇA, 2015, p.1).

Sabemos que as sociedades, do reino animal, à que pertencemos diga-se de passagem, funciona através de sistemas, e reproduz efeitos de acordo com a sua possibilidade de adequação. O fator humanístico, está ligado com a nossa capacidade de sentir, e de guardar informações.

Reconhecendo isso, sempre houve interesse por parte dos legisladores, de que os danos dos conflitos pudessem ser amenizados da melhor forma possível, tanto é que em todos os casos, em um primeiro momento, sempre buscou-se a conciliação das partes. Preconiza o artigo 649 NCPC/15:

Art. 694. Nas ações de família, todos os esforços serão empreendidos para a solução consensual da controvérsia, devendo o juiz dispor do auxílio de profissionais de outras áreas de conhecimento para a mediação e conciliação. Parágrafo único. A requerimento das partes, o juiz pode determinar a suspensão do processo enquanto os litigantes se submetem a mediação extrajudicial ou a atendimento multidisciplinar (BRASIL, 2015). 
Debaixo desse teto, com a visão de que os processos judiciais seriam tão somente uma questão de consciência, de que os conflitos são a consequência dos homens não saberem viver em sociedade, ante o fato de não conhecerem as razões de suas vontades, tão menos a possibilidade de controlar seus impulsos, o Direito Sistêmico tem trazido uma Nova Era para todos as partes que têm buscar dar fim ao conflito e seguir em frente.

A ferramenta tem sido tão efetiva, que mesmo nos casos em que havia resistência por uma das partes, o índice de acordos chegou a 91\%, vejamos:

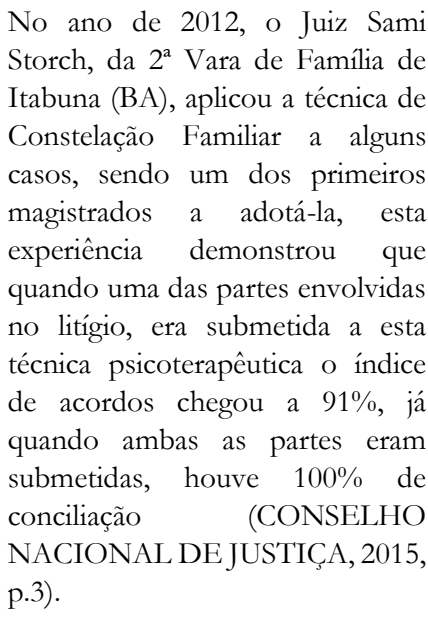

Quem poderia rejeitar uma ferramenta capaz não só de por fim ao processo, por fim ao conflito, mas que pode ir além e trazer o amor em grande escala nas relações interpessoais, absorção dos assuntos e maior respeito e consideração em relação à outra parte? É o que nos mostra o Juiz Storch em seus relatos:

As técnicas aplicadas vêm auxiliando na efetivação de conciliações verdadeiras entre as partes. Durante e após o trabalho com constelações, os participantes têm demonstrado boa absorção dos assuntos tratados, um maior respeito e consideração em relação à outra parte envolvida, além da vontade de conciliar - o que se comprova também com os resultados das audiências de conciliação realizadas semanas depois (os índices de acordos superam os $90 \%$ ) e com os relatos das partes e dos advogados (STORCH, 2015, p. 22).

Percebe-se que na relação conflituosa, as partes busca sempre "vencer", quem vai levar a melhor, quem vai ganhar, e com a aplicação da Constelação Familiar no Direito Sistêmico, existe um salto gradativo nos interesses, passa-se da posição ofensiva, para uma posição consciencial, uma posição amigável, diante da compreensão da dor que permeia os interesses mais vis que movimenta cada uma das partes:

Posteriormente, quando da
realização das audiências de
conciliação, os acordos acontecem
de forma rápida e até emocionante,
pois os que participaram das
vivências tendem a desarmar seus
corações e reconhecer que, por trás
das acusações e dos rancores
mútuos, existe um sentimento de
amor verdadeiro e a dor da
frustração (STORCH, 2015, p. 22).

Como se demonstrou, muitos indivíduos estão ligados na relação conflituosa, são aqueles que recebem os danos indiretos, os filhos, os parentes mais próximos, os amigos, logo, o Direito Sistêmico, indo diretamente ao ponto, possibilita um índice de felicidade muito maior à todos os evolvidos, direta ou indiretamente. É o que segue:

Dessa forma, além de contribuir para o aperfeiçoamento da Justiça, a prática também auxilia a melhorar a qualidade dos relacionamentos nas famílias que, sabendo lidar melhor com os conflitos, podem viver mais em paz e assim proporcionar um ambiente familiar melhor para o crescimento e desenvolvimento dos filhos, com respeito e consideração à importância de cada um. Consequência natural disso é a melhora nos relacionamentos em geral e a redução dos conflitos na comunidade (STORCH, 2015, p. 25). 
Diante da moral verdade, precisamos entender que os relacionamento precisa ser baseados nos sentimentos de compaixão e amor ao próximo, isso expande de forma significativa a afetividade do ser humano, indo muito além, amplia todo o conhecimento sobre afetividade, viabilizando a compreensão da sua própria natureza.

Logo, o Direito Sistêmico tem ampliado dessa forma a aquisição de conhecimento e desenvolvimento do raciocínio:

\begin{abstract}
Os conflitos surgem no meio de relacionamentos e, nas palavras de Bert Hellinger, "os relacionamentos tendem a ser orientados em direção a ordens ocultas.[...] O uso desse método faz emergir novas possibilidades de entender o contexto dos conflitos e trazer soluções que causam alívio a todos os envolvidos". $\mathrm{O}$ mero conhecimento dessas ordens ocultas, descritas por Hellinger como as "ordens do amor", permite a compreensão das dinâmicas dos conflitos e da violência de forma mais ampla, além das aparências, facilitando ao julgador adotar, em cada caso, o posicionamento mais adequado à pacificação das relações envolvidas (STORCH, 2015, p. 23).
\end{abstract}

A relação entre os indivíduos, quando resolvidos os conflitos, devolvem o pertencimento à cada um, e proporcionam um grau de satisfação inquestionável. É conclusivo que o Direito Sistêmico, tem trazido novos caminhos e modelos para compreender os caminhos da vida, uma evolução intelectual que responde mais satisfatoriamente a razão das coisas, e nos aproxima de uma compreensão sóbria das leis naturais.

Como seres humanos vivendo em sociedade, estamos aprendendo a reconhecer que todos os indivíduos precisam ter o seu lugar e reconhecimento, é o que nos demonstra Storch:
Uma das bases do direito sistêmico é a consideração pela pessoa e pela bagagem que ela traz (família). Um indivíduo não pode ser tratado isolado, ele tem que ser encarado como um sistema, formado por ele próprio, pelo pai e pela mãe. Se quisermos conhecer alguém ou a nós mesmos nós precisamos assimilar a origem desse ser. Todos gostam de ser reconhecidos. Muitas pessoas ingressam com processos na Justiça por conta de um motivo, mas quando é feita a análise mais profunda, é possível verificar que o problema maior é que elas foram desconsideradas pelo outro ou sofreram um gesto de não reconhecimento (STORCH, 2015, p.21).

Percebe-se há muito, que o interesse da espécie não é tão somente a busca de poder e o interesse em se reproduzir e perpetuar a espécie, mas também, o desenvolvimento de uma revolução da teoria das espécies, para que alguns pontos obscuros na evolução histórica do homem possam ser trazidos à tona.

Entende-se o Direito Sistêmico como uma proposta para a evolução, poder evoluir dentro de diferentes possibilidades, possibilidades estas mais harmoniosas, depuradas, é o que nos retrará Silva:

\footnotetext{
Queremos mostrar como a observância e a aplicação das Leis Sistêmicas, através da própria Constelação Sistêmica Familiar, uma abordagem eminentemente empírico-filosófica, sem qualquer ligação religiosa, holística ou metafísica, podem ajudar a encontrar a reconciliação e a paz nas famílias, já que a partir da sua percepção é possível alcançar as questões e disputas processuais dos litigantes com um olhar mais amplo, imparcial e verdadeiro (SILVA, 2016, p.12)
}

Entendemos que a abordagem de Silva sobre a separação de qualquer ligação religiosa, holística ou metafísica, podem ajudar a encontrar a reconciliação e a paz nas famílias, uma vez que fazemos parte de uma 
enorme gama de crenças, o que poderia criar uma certaz resistência na aceitação da ferramenta.

O Constelador, conhecedor desta faculdade, não precisa então ser um operador do Direito, nem ter conhecimento algum das leis humanas, tão somente, o conhecimento da força eletromagnética organizada, agregada para fins de organização e manutenção da matéria (atômica/informação), que define a característica das espécies e determina sua evolução, vejamos:

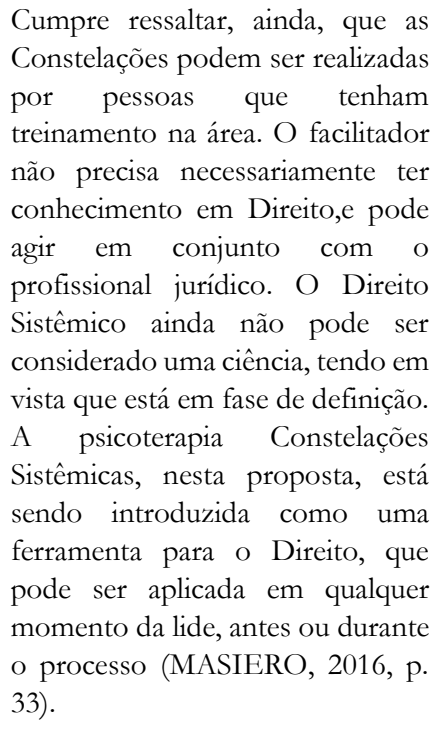

Aquilo que a física quântica hoje caracteriza como sendo o vácuo quântico, a mônada universal da composição do universo, tudo está sujeito à mudanças, logo, se pode mudar se contém em si o princípio da vida, está sujeito à evolução.

Com a compreensão de que somos todos feitos de átomos (onda/partícula), e de que os átomos são compostos de Hertz, Quarks, Bósons de Higgs, toda forma de agregação orgânica é energética, e está em vibração, é informação, que não se cria, não se perde, mas sim, se transforma, devemos entender que o constelador é possuidor dessa chave universal, do conhecimento do campo morfogenético, conhecedor de que muitas vezes o indivíduo, em sua forma atual não pode mudar sozinho, e que este processo só pode ser interno, em sua essência.
É por isso que as audiências em que se utiliza a constelação são relatadas como uma oportunidade de se visualizar algo totalmente único, mágico:

Achei que iria encontrar uma audiência comum de conciliação, mas ao chegar me deparei com uma técnica muito interessante, que é a constelação familiar. Tanto eu quanto as partes estávamos um pouco céticos no início, mas quando chegou a vez deles, o envolvimento e a comoção foram tão grandes, que não tínhamos mais como negar que funciona (MEDEIROS, 2016, reportagem).

Toda a percepção humana é feita através de ondas, o que entra através do nosso nervo ótico, do olfato, do paladar, do sistema auditivo, do tato, é uma informação através de um estímulo de uma onda eletromagnética.

Independente de fazer crer aqui nos conceitos mais aprofundados de ciência, o que se sabe é que o Direito Sistêmico é uma nova ferramenta de desenvolvimento humano, capaz de mudar todos os paradigmas no campo do direito, saindo assim de uma zona de conforto que se arrastava há séculos.

\section{DA APLICAÇÃO PRÁTICA E TEÓRICA DO DIREITO SISTÊMICO NO BRASIL}

Como as relações interpessoais estão ligadas com interesses de fatores carregados de energia emocional, a lei positivada não pode oferecer uma solução efetiva em todos os casos, esse é um entendimento que vem tomando cada vez mais força dentro do cenário jurídico, senão vejamos:

Isso porque, na prática, mesmo tendo as leis positivadas como referência, as pessoas nem sempre se guiam por elas em suas relações. Os conflitos entre grupos, pessoas ou internamente em cada indivíduo são provocados em geral por causas mais profundas do que um mero desentendimento pontual, e os autos de um processo judicial dificilmente refletem essa 
realidade complexa. Nesses casos, uma solução simplista imposta por uma lei ou por uma sentença judicial pode até trazer algum alívio momentâneo, uma trégua na relação conflituosa, mas às vezes não é capaz de solucionar verdadeiramente a questão, de trazer paz às pessoas. (STORCH,2015, p. 37)

O Direito Sistêmico tem suas raízes fundadas nos conceitos Sociológicos, Antropológicos e Psicológicos, pois, como dizia Jung, pessoas feridas, ferem pessoas, e dentro de um conhecimento básico do Contrato Social por Rousseau, é necessário entender a responsabilidade para com os indivíduos desequilibrados, mas também, para com a segurança e desenvolvimento de todo um núcleo social em que se inserem estes indivíduos. Veja-se o conceito de Storch neste sentido:

\begin{abstract}
Uma pessoa atormentada por motivos de origem familiar pode desenvolver uma psicose, tornar-se violenta e agredir outras pessoas. Quem tem a ver com isso? Todos. Toda a sociedade. Adianta simplesmente encarcerar esse indivíduo problemático, ou mesmo matá-lo (como defendem alguns)? Não. Se ele tiver filhos que, com as mesmas raízes familiares, apresentem os mesmos transtornos, o problema social persistirá. (STORCH, 2015, p.37)
\end{abstract}

E continua Storch explicando que existem limites sutis que podem garantir uma aplicação efetiva do procedimento:

Que fique bem claro: isso não impede que o pai e a mãe discutam as questões necessárias, judicialmente ou não, desde que isso se dê entre eles, sem o envolvimento dos filhos, nem que o juiz decida as demandas que lhe forem postas. ( STORCH, 2015, p.23)
Percebe-se a necessidade de uma nova visão na aplicação do Direito para resolução dos conflitos, visão está que pode ser aplicada diante da efetividade do Direito Sistêmico, uma vez que este novo campo trabalha da forma mais benevolente possível.

\subsection{Da Constelação Familiar} como auxiliador nos procedimentos consensuais de solução de controvérsias

A Constelação é o acesso à outras modalidades de fenômenos humanísticos, elevando o Juiz que se incumbiu da figura de mediador à um patamar muito mais elevado, é o que ensina Targa:

$$
\begin{aligned}
& \text { O Juiz que se incumbiu de um } \\
& \text { espírito mediador eque conhece as } \\
& \text { técnicas que podem induzir as } \\
& \text { partes a um acordo adequado, } \\
& \text { consegue excelentes resultados, } \\
& \text { inclusive fazendo com que } \\
& \text { discutam questões que não vieram } \\
& \text { à baila no processo, mas que estão } \\
& \text { no cerne do conflito. (TARGA, } \\
& \text { 2004, p.12) }
\end{aligned}
$$

É bem sabido que os fatores que definem nossa forma de ver o mundo e de agir sobre ele são os fatores constitutivos de nosso mundo, logo, podemos dizer que o pensamento dos paradigmas inseridos na humanidade sustenta o mundo em que vivemos.

O autor Franke Bryson faz uma abordagem que aponta a efetividade do Direito Sistêmico na resolução dos conflitos:

A Constelação (Direito Sistêmico), apresentada por Bert Hellinger, tem como finalidade a busca por soluções de conflitos e de possíveis problemas que advém deles, além de questões comportamentais e de dificuldade de relacionamento, entre outros. O uso das Constelações surge para dar suporte às estruturas familiares, partindo do problema existente para uma suposta ou possível resolução em curto período de tempo. (FRANKE-BRYSON, 2013, p. 31) 
Ainda por Bryson continua em sua abordagem, fazendo uma colocação de que a externalização (sentimentos/desordem) dos elementos internos é a solução, diante da visualização do trauma muitas vezes oculto.

Através desta aproximação com o conflito, não estamos mais trabalhando no famigerado jogo de interesses entre quem ganha ou quem perde, vejamos:

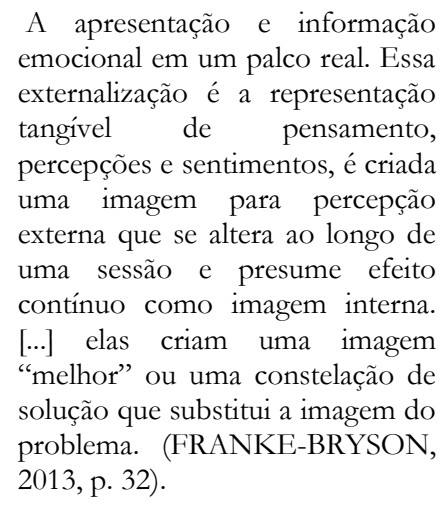

À partir disso, a ideologia de uma justiça extra e supra mundana, contínua e ininterrupta, caracteriza a consciência de um bem supremo, onde o Direito Sistêmico permite aos indivíduos darem um sentido ao quadro que vivenciam, é um mecanismo balizador que direciona o conflito à ser resolvido. Continua Bryson:

\begin{abstract}
No contexto de Hellinger sobre Constelação Familiar, os clientes configuram a imagem interna de suas famílias. Ao fazerem isso, os elementos e seus sistemas, ou seja, os membros de suas famílias são simbolicamente retratados pelos participantes do grupo em seus relacionamentos uns com os outros. O cliente posiciona cada pessoa no seu lugar que parece se ajustar mais a ela, segundo sensação ou intuição. Os representantes descrevem suas percepções, sensações e seus estados emocionais, e vivenciam sua posição no sistema em diferentes graus de satisfação e descontentamento" (FRANKEBRYSON, 2013, p. 33)
\end{abstract}

O Direito Sistêmico funciona como forma de terapia em grau elevado, uma forma de cura e preenchimento do vazio à que os indivíduos se submeteram de maneira inconsciente, quando percebe sozinho através da Constelação quando suas escolhas lhe são danosas. Aponta Targa:

[...] todo aquele que conta qualquer problema que o aflija, é natural, expurga desse relato todas as questões que não lhe são interessantes e as expõe utilizando seu próprio ponto de vista. Quando relatamos fatos, nem sempre sobre eles discorremos em sua inteireza, apresentamos apenas uma ideia ao nosso interlocutor de como ocorreram. No geral, suprimos as situações que nos são desfavoráveis [...] (TARGA, 2004, p. 32)

Prossegue Targa, informando que a grande dificuldade seria o fato de que o mediador do conflito não resolveria o conflito de interesses em sua integralidade, é o que segue:

\begin{abstract}
A grande dificuldade é que, com isso, o juiz, ou quem quer que seja que atue como mediador da relação, não resolve o conflito de interesses em sua integridade, posto que sequer conheceu integralmente ou em todas as suas nuances. (TARGA, 2004, p.32).
\end{abstract}

A cura proporcionada pelo Direito Sistêmico permite às partes superar os entraves de seus próprios erros, uma vez que a experiência os modifica e os faz crescer, diante do fato de que o contato com o outro proporciona um elo intersubjetivo entre as partes.

É o que Bryson nos demonstra quando fala da orientação por meio do entendimento da totalidade dos fatos:

Tal análise envolve um conjunto de fatores intrínsecos ao problema, interpretando-O as diversas vertentes desse, e mais, todo o conteúdo simbólico, muitas vezes, inconsciente e silencioso que servem de influência e justificativa para o problema em questão. Assim, a constelação funciona como uma orientação por meio do entendimento da totalidade dos 
fatos. (FRANKE-BRYSON, 2013, p. 32)

A Constelação Familiar age diretamente no foco do problema, sendo que trabalha com elementos de consciência psicológica, que estão enraizadas no sistema de crenças familiares e que atrapalham o desenvolvimento dos indivíduos, é o caso da aposentada Heloísa:

A servidora aposentada Heloísa (nome fictício), 65 anos, foi encaminhada há um ano, para saldar uma dívida que superava seu patrimônio. Heloísa revela que a constelação foi fundamental para que pudesse identificar onde estava o problema familiar, que fazia com que ela repetisse os padrões de seu pai: quando estava bem financeiramente, arrumava um jeito de entrar no vermelho e contrair mais dívidas. Ela participou de três constelações e hoje já está com quase $60 \%$ da dívida paga. (CNJ, 2016, p.1)

A ferramenta humaniza os processos, sendo desnecessário demonstrar que o Direito Sistêmico tem uma capacidade enorme de influenciar positivamente as partes a adotarem uma postura mais amigável:

A técnica foi aplicada em cerca de 50 processos, desde março, alcançando índice de acordos de $86 \%$, com a participação das duas partes na dinâmica. Depois de participarem da constelação, as partes ficam mais dispostas a chegar a um acordo. Isso é fato. A abordagem, além de humanizar a Justiça, dá novo ânimo para a busca de uma solução que seja benéfica aos envolvidos. Quem faz, percebe uma mudança em sua vida. (CNJ, 2016, p.1)

A Constelação Familiar tem a capacidade de trabalhar os valores que nos são transmitidos durante as nossas vidas através da nossa cultura (diante do campo universal de informações), o que interfere em nossa capacidade de julgar as coisas.
Com a obtenção de uma nova consciência, é proporcionado ao indivíduo que modifique suas disposições íntimas, criticamente, de modo que essas transformações privilegiam assim a justiça e os valores perenes do homem:

A constelação ajudou a amenizar o conflito deles com as famílias adotivas e, em outras situações, ajudou na reaproximação com os pais biológicos. Também foram percebidas mudanças positivas dos jovens no trato com as cuidadoras.(CNJ, 2016, p.1)

Os índices de efetividade do Direito Sistêmico tem se demonstrado muito acima das expectativas, tendo conseguido um índice de 100\% de acordos em conflitos familiares ao utilizar a técnica antes das audiências de conciliação de acordo com os relatórios do $\mathrm{CNJ}$.

Na época, em 2012, a técnica foi aplicada aos cidadãos do município de Castro Alves, a 191 quilômetros de Salvador. Das 90 audiências nas quais pelo menos uma das partes participou da vivência de constelações, o índice de conciliação foi de $91 \%$.

\subsection{Do Sucesso da Constelação, Do Direito}

\section{Sistêmico e Do envolvimento da \\ Espiritualidade}

Estamos continuamente sendo banhados com todos os tipos de radiação do espaço, sendo que, além da radiação eletromagnética, certos tipos de radiação de partículas originárias do espaço exterior são detectáveis na terra.

Conforme apresentado no tópico referente à filosofia idealista e a ciência da física quântica, o que se percebe no presente estudo não é novidade, somos seres grupais, temos vínculos energético-emocionais, e isso foi observado na aplicação do Direito Sistêmico:

Durante a introdução da terapia na Vara de Família do município, faziam-se três reuniões - terapia 
em grupo - com três casos constelados por dia. Segundo dados de 2012 e 2013, os resultados obtidos nas audiências, em sua maioria de casos de guarda, alimentos ou divórcio mostraramse positivos. $91 \%$ de conciliações em audiências nas quais uma das partes havia participado das constelações e 100\% de acordos naquelas em que ambas as partes foram submetidas à terapia proposta. (CNJ, 2014, p.1)

Poderíamos dizer facilmente que o Direito Positivado também "resolvia os conflitos", não é mesmo? Assim como apresentado por Hellinger que os grupos formam uma corrente invisível e sem barreira de espaço, a magia se torna realidade quando a constelação apresenta 91\% de efetividade mesmo quando apenas uma das partes envolvidas aceita realizar a mediação sistêmica.

Faz-se compreender assim que Direito Sistêmico não só resolve satisfatoriamente os conflitos, mas também traz paz aos envolvidos, fazendo com que resolvam diversos conflitos, explica Storch:

Storch na sua trajetória como jurista, primeiro na advocacia e depois na magistratura, percebeu que os relacionamentos humanos nem sempre se orientam pelas leis positivadas, que muitos dos conflitos vivenciados entre grupos ou entre indivíduos têm origem em questões mais profundas do que os fatos trazidos aos autos de um processo judicial, percebeu ainda que na presença de uma complexidade maior do que o que pode ser aparentemente percebido, os ditames das leis ou da decisão judicial não sanam a questão trazida ao direito. Em sua experiência na magistratura observou que mesmo quando uma ou ambas as partes se sentiam aliviadas com o proferir da sentença, a questão permanecia, vindo posteriormente exigir sua resolução, retirando a tranquilidade e, muitas vezes, trazendo novamente à esfera jurídica os envolvidos. (CÉSPEDES, 2017, p. 37)
Estudando as constelações, temos a clara visão de que Bert Hellinger busca averiguar se existe alguém no sistema familiar que esteja emaranhado nos destinos anteriores dos membros dessa família (acesso ao self, consciência não-local), trazendo-se à luz um conflito que esteja sendo repetido (cargas de memória gravadas no espaço não-local, na consciência e no DNA), a pessoa consegue se libertar mais facilmente, estas seriam as ordens superiores explicadas por Storch:

Da análise do Direito sob uma
ótica baseada nas ordens
superiores que regem as relações
humanas, segundo a ciência das
Constelações Sistêmicas.
(STORCH, 2010, p. 12)

Analisando todo o contexto, fica claro que não se pode haver uma separação do fator filosóficoespiritual, muito menos do fator científico-moral que abrange o tema, vivemos uma nova era da compreensão humana, momento em que passamos a atingir o ponto chave dos conflitos humanos, e quem sabe, estamos chegando muito perto de uma cura coletiva.

Tudo isso, com a maior afetuosidade e honra ao sistema familiar, utilizando-se as bases do amor, explica Storch:

Inicialmente, discute-se sobre os vínculos sistêmicos familiares, sobre os motivos que levam às crises e como enfrentá-las, de modo a não envolver os filhos no conflito, visto que, estes sempre são os mais prejudicados. Após, realiza-se uma meditação, em que os presentes buscam o real sentimento do amor. Por fim, tem contato direto com as Constelações, uma vez que, as partes podem constelar a sua própria questão, podem participar como representante da Constelação de outra pessoa ou simplesmente estarem como observadores (STORCH, 2016, p. 12).

Nos estudos de Bert Hellinger, o mesmo trata de nos demonstrar que a vida vem de longe, e nós não 
podemos precisar qual seria a origem, logo, olhar com amor para essa origem é algo religioso, não olhando assim para o que está perto, mas para o que está longe, compreender isso é aceitar que as constelações são sim um ritual de cura, daí se deriva o fator emocionante presenciado nas audiências de conciliação:

Posteriormente, quando da realização das audiências de conciliação, os acordos acontecem de forma rápida e até emocionante, pois os que participaram das vivências tendem a desarmar seus corações e reconhecer que, por trás das acusações e dos rancores mútuos, existe um sentimento de amor verdadeiro e a dor da frustração (STORCH, 2016, p.13).

Inegável que além de se oportunizar um desafogamento do judiciário, vem sendo capaz de trazer melhoria de vida às pessoas envolvidas, e mais, um presente desenvolvimento social, vejamos:

\begin{abstract}
Esta prática tende, tão somente em reduzir os processos judicias, como também trazer qualidade de vida a uma família até então estava fragmentada e ferida, de modo que, auxilia seus membros a solucionarem suas divergências e a criarem um ambiente harmônico e de paz, onde seus filhos poderão crescer mais saudavelmente (STORCH, 2016, p.10).
\end{abstract}

Poderíamos dizer, assim como Hellinger, que o método fenomenológico do Direito Sistêmico tem como direcionamento o trabalho das forças positivas em ação, tendo como objetivo primordial a alma e a família. Podemos assim ter uma compreensão sobre o equilíbrio e a paz da atividade da constelação:

O Direito Sistêmico, em termos técnico-científico, é um método sistêmico-fenomenológico de solução de conflitos, com viés terapêutico, que tem por escopo conciliar, profunda e definitivamente, as partes, em nível anímico, mediante conhecimento e a compreensão das causas ocultas geradoras das desavenças, resultando daí paz e equilíbrio para os sistemas envolvidos (ROSA, 2016,p.1).

$\mathrm{Na}$ utilização do Direito Sistêmico, o fator psicológico-espiritual, busca uma solução que satisfaça todos os membros da constelação, colocando cada um no lugar certo, onde deveria estar em compreensão do seu direito.

Percebe-se que o trabalho de Hellinger traz as ordens do amor, assim sendo, todos veem reconhecida a própria dignidade e se sentem bem. É o que nos relata Storch:

Logo, questões relacionadas à violência, dificuldade de se relacionar, diversos tipos de bloqueios, inseguranças, vícios, problemas no trabalho, podem ser potencialmente resolvidos através deste método (STORCH, 2016, p. 15).

O Direito Sistêmico se tornou tão efetivo que tem sido utilizado com grande margem de efetividade, o que é apontado pelo TJ/SC como uma visão transdiciplinar:

O projeto envolve uma visão transdisciplinar não só por abrir portas para várias técnicas, mas também por humanizar todos os envolvidos, desde a magistrada até as partes, com um grande entendimento sobre todos os aspectos da vida que interferem inconscientemente na tomada de decisões (TJSC, 2017, p.1)

O Direito Sistêmico se baseia nas ordens da constelação sistêmica, a solução do conflito só se dá em um nível espiritual em que se consegue amar, respeitar e honrar todos os envolvidos, isso é muito importante, e esse é o resultado de uma observação cuidadosa, de um estudo apurado, e não de qualquer ensino ou tradição religiosa. 


\section{CONSIDERAÇÕES FINAIS}

No presente trabalho buscou-se demonstrar o amplo conceito do que é o Direito Sistêmico e a Constelação Familiar através do tripé de sustentação moral, filosofia e ciência; buscando responder a problemática questão da necessidade de utilização de métodos atualizados, ainda não regulamentados, decorrentes de máximas pós positivistas, utilizando-se da metodologia científica e investigativa.

Para alcançar objetivos mais amplos, a investigativa utilizou-se da metodologia bibliográfica com abordagem qualitativa, metodologia legislativa e jurisprudencial, podendo se dizer que no quesito da filosofia idealista e quântica, buscou trabalhar de maneira extensiva a metodologia qualitativa, declinando por uma reprodução quantitativa, sem contar os elementos delineados no conceito científico.

Para tal, faz-se necessário desenvolver a compreensão de que vivemos em uma sociedade com bases morais, com um direcionamento apontado para ética, pois, dentro de uma sociedade conservadora, para que exista aceitação, pressupõe-se indispensável moralidade. Diante desse conceito abordou-se a imoralidade do ceticismo e a imoralidade arrogante da de uma sociedade que, algumas vezes, esquece a projeção social de futuro, ainda quando os dados e índices de solução do conflitos demonstram um ponto no futuro que vale a presente investigativa.

Também, indispensável foi abordar o conceito filosófico, levantando os bases deste pensamento, mantendo a credibilidade científica que evita a utilização do viés fundamentalista. Dito isto, o capítulo busca deixar aberta a discussão para que todo e qualquer indivíduo possa vir a questionar seriamente os elementos apresentados.

A junção dos capítulos faz um apanhado de todas as regras sociais para aceitação de um conhecimento, partindo deste ponto como uma forma da melhor do que é o Direito Sistêmico e a razão do êxito das constelações familiares como reais influenciadores dos altos índices de soluções litígios e casos concretos.

Feita essa apresentação, os capítulos seguintes abordam diretamente a relação do Direito Sistêmico com os envolvidos, qual a visão atual do Poder Judiciário em sua utilização, e o que podemos esperar dessas ferramentas para o futuro

Por isso, demonstra-se a importância dessa ligação com a ideia de self, do material com o espiritual, do local com o não local, do céu e da terra, haja vista que conhecimentos como os empregados pelo Direito Sistêmico, assim como a Filosofia Idealista e Filosofia Quântica demonstram que, parafraseando Hamlet à Horácio, há mais coisas entre o céu e a terra do que se pode imaginar a nossa vã filosofia e a física clássica.

A presente proposta foi de abordar e aprofundar ainda mais os pensamentos de Hellinger, fazendo uma junção com a prática pioneira de Storch que foi tão expressiva para a prática forense e na solução de litígios no caso concreto.

Portanto, os objetivos aqui demonstrados foram satisfeitos e, ao final, declinaram-se no sentido de que existem bases de conhecimento concreto para verificar a segurança sobre o que é o Direito Sistêmico e a Constelação Familiar, observando a reprodução prática de aplicação do Direito Sistêmico, bem como a eficiência dos resultados positivos de uma prática que se utiliza de outras matérias, dentre as quais, a psicologia.

\section{REFERÊNCIAS BIBLIOGRÁFICAS}

BANDEIRA, Regina. Juiz consegue $100 \%$ de acordos usando técnica alemã antes das sessões de conciliação, 17 de novembro de 2014. Portal CNJ. Notícia. Disponívelem<http://www.cnj.jus.br/noticias/ cnj/62242-juiz-consegue-100-de-acordos- 
usando-tecnica-alema-antes-das-sessoes-deconciliacao $>$. Acesso em 05 de novembro de 2018.

BRASIL, Lei $\mathrm{n}^{\mathrm{o}}$ 13.105, de 16 de março de 2015. Disponível em: <http://www.planalto.gov.br/ccivil_03/_ato20 15-2018/2015/lei/113105.htm>. Acesso em 12 de abril de 2018.

BRASIL, Lei $\mathrm{n}^{\circ}$ 13.140, de 26 de junho de 2015. Disponível em: <http://www.planalto.gov.br/ccivil_03/_ato20 15-2018/2015/lei/113140.htm>. Acesso em 12 de abril de 2018.

BRASIL, Lei $\mathrm{n}^{\circ}$ 9.307, de 23 de setembro de 1996. Disponível <http://www.planalto.gov.br/ccivil_03/Leis/L 9307.htm>. Acesso em 12 de abril de 2018.

CARMO, Maria Scarlet. Uma Breve Apresentação sobre a Constelação Sistêmica Fenomenológica. São Paulo: Editora Atlas, 2015. 13 p.

CÉSPEDES, Adele Speck Rendón. A Constelação Familiar aplicada ao Direito Brasileiro a partir da Lei de Mediação. Monografa apresentada ao curso de Direito da Universidade Federal de Santa Catarina, Florianópolis, 2017.

CLEMES,Carina Gassen, SILVA, Clarice Botelho. O instrumento da Constelação Familiar à luz do direito de família, como um meio alternativo de resolução de conflitos. Anais do I Congresso Acadêmico de Direito Constitucional. São Paulo, 2016.

ONSELHO NACIONAL DE JUSTIÇA. Juiz consegue $100 \%$ de acordos usando técnica alemã antes das sessões de conciliação. 2014. Disponível em:

$<$ http://www.cnj.jus.br/noticias/cnj/62242-juizconsegue-100-de-acordos-usando-tecnicaalema-antes-das-sessoes-de-conciliacao >. Acesso em 12 de novembro de 2018.

CONSELHO NACIONAL DE JUSTIÇA. Resolução $\mathrm{n}^{\circ} \mathbf{1 2 5}$, de 29 de novembro de 2010. Disponível em: <http://www.cnj.jus.br/busca-atosadm?documento=2579>. Acesso em 23 de outubro de 2018.

HELLINGER, Bert. A fonte não precisa perguntar pelo caminho. $2^{a}$ edição. Minas Gerais: Atman, 2007.

HELLINGER, Bert. Constelações Sistêmicas e Familiares. São Paulo: Editora Cultrix, 1999.252 p.

HELLINGER, Bert. Ordens do Amor. São Paulo: Editora Cultrix, 2016. 270 p.

MASIERO, Ana Carolina. Aplicabilidade da Constelação Sistêmica no âmbito do Direito. Minas Gerais: UFMG, 2016. 5 p.

ROSA, Amilton de Plácido da. Direito Sistêmico e Constelação Familiar, 2 de setembro de 2016. Entrevista. Disponível em: <http://www.cartaforense.com.br/conteudo/e ntrevistas/direito-sistemico-e-constelacaofamiliar/16914>. Acesso em 25 de outubro de 2018.

STORCH, Sami. Direito Sistêmico: primeiras experiências com constelações no judiciário. In Filosofia, Pensamento e Prática das Constelações Sistêmicas - $n^{0}$ 4. São Paulo: Editora Conexão Sistêmica, 2015. 